\title{
Molluscicidal efficacies of different formulations of niclosamide: result of meta-analysis of Chinese literature
}

\author{
Guo-Jing Yang ${ }^{1}$, Wei Li ${ }^{1}$, Le-Ping Sun ${ }^{1}$, Feng Wu${ }^{1}$, Kun Yang ${ }^{1}$, Yi-Xin Huang ${ }^{1}$, Xiao-Nong Zhou ${ }^{2 *}$
}

\begin{abstract}
The control efforts on Oncomelania hupensis, the intermediate snail host of Schistosoma japonicum, cannot be easily excluded from the integrated approach of schistosomiasis control in China. Application of chemical compounds, molluscicides, in snail habitats is a common method for snail control in addition to environmental modification. We conducted a systematic review and meta-analysis to assess the molluscicidal effects of the currently recommended 50\% niclosamide ethanolamine salt wettable powder and a new $4 \%$ niclosamide ethanolamine salt powder developed by Chinese researchers. Literature was searched from three Chinese databases, i.e. Chinese Biomedical Database, VIP Database and Wanfang Database, on field mollusciciding trials of niclosamide in China (from January 1, 1990 to April 1, 2010). Molluscicidal effects on reduction of snail population of the $50 \%$ or $4 \%$ niclosamide formulations in field trial were evaluated 3 days, 7 days or 15 days post-application. Out of 90 publications, 20 papers were eventually selected for analysis. Publication bias and heterogeneity tests indicated that no publication bias existed but heterogeneity between studies was present. Meta-analysis in a random effect model showed that the snail mortality of 3,7 and 15 days after spraying the $50 \%$ niclosamide ethanolamine salt wettable powder were $77 \%$ [95\%Cl: $0.68-0.86], 83 \%$ [95\%Cl: $0.77-0.89]$, and $88 \%$ [95\%Cl: $0.82-0.92]$, respectively. For the $4 \%$ niclosamide ethanolamine salt powder, the snail mortality after 3, 7 and 15 days were $81 \%$ [95\%Cl: 0.65-0.93], 90\% [95\%Cl: $0.83-0.95$ ] and $94 \%$ [95\%Cl: 0.91-0.97], respectively. Both are good enough to be used as molluscicides integrated with a schistosomiasis control programme. The $4 \%$ niclosamide ethanolamine salt powder can be applied in the field without water supply as the surrogate of the current widely used $50 \%$ niclosamide ethanolamine salt wettable powder. However, to consolidate the schistosomiasis control achievement gained, it is necessary to continuously perform mollusciciding more than twice annually in the field.
\end{abstract}

\section{Introduction}

The transmission records of schistosomiasis japonica, a disease prevalent in the Yangtze River valley and southern part of China, can be traced back over 2,000 years [1]. The distribution of the disease was determined by the distribution of its exclusive intermediate host snail, i.e. Oncomelania hupensis [2-4]. Geographically, O. hupensis habitats can be divided into three ecological types: (i) lake and marshland regions; (ii) hilly and mountainous regions; and (iii) plain regions with water networks [2]. Large-scale disease control programmes

\footnotetext{
* Correspondence: ipdzhouxn@sh163.net

${ }^{2}$ National Institute of Parasitic Diseases, Chinese Center for Disease Control and Prevention, 207 Rui Jin Er Road, Shanghai 200025, People's Republic of China

Full list of author information is available at the end of the article
}

were initially carried out in the 1950s by the Chinese government from central to local levels, putting a strong emphasis on snail control, including environmental modification and the application of chemical molluscicides $[1,5]$. The achievements were consolidated through a 10-year World Bank Loan Project (WBLP) for schistosomiasis control starting in 1992. Prevalence and morbidity reached the lowest level in 2000, which is partially explained by mass chemotherapy $[3,4,6]$. Soon after the ending of WBLP in 2001, the disease emerged or reemerged in some regions [7], which drew attention of the government again and a new integrated control program was launched in 2004 with emphasis on health education, access to clean water and adequate sanitation, mechanization of agriculture and fencing of water buffaloes, along with chemotherapy $[8,9]$. The importance of
C Biomed Central

(c) 2010 Yang et al; licensee BioMed Central Ltd. This is an Open Access article distributed under the terms of the Creative Commons Attribution License (http://creativecommons.org/licenses/by/2.0), which permits unrestricted use, distribution, and reproduction in any medium, provided the original work is properly cited. 
the mollusciciding in the integrated control of human schistosomiasis has gone through cyclical changes over the past 6 decades. For a time, it was hoped that chemotherapy alone would achieve significant morbidity control. However, many recent studies have shown that control programmes based on chemotherapy alone can provide only a temporary reduction in transmission $[10,11]$. Snail control, therefore, is important in integrated schistosomiasis control as the disease is environment-related [12,13]. Favourable environmental conditions required for disease transmission still exist in endemic areas, and it would be difficult to maintain the current low level of infection if dense populations of the intermediate host persist [14]. In addition, ecological transformations bring about new challenges for control, most notably the Three Gorges dam project, and the South-to-North Water Transfer Project as well as global warming $[15,16]$.

Application of chemical compounds in snail habitats is a common method for elimination of intermediate host snails, in addition to environmental modification, such as cementing canals, re-adjusting irrigation systems, etc $[14,17]$. Niclosamide has been recommended by WHO as a sole molluscicide since the 1960s [18] and is still the molluscicide of choice [19]. In China, other synthetic molluscicides, such as sodium pentachlerophenate $(\mathrm{NaPCP})$, were widely used before WBLP. Due to the safety concerns and severe problems of environmental pollution, NaPCP has been banned from use in China [20]. Niclosamide is the only molluscicide applied currently in the field for snail control in China, although there have been many formulations of niclosamide developed over the past few decades. One niclosamide formulation is a $50 \%$ niclosamide paste known as schistosomiasis-67 paste, and has contributed to snail control at low cost. But this formula as a paste form easily clogs and in turn blocks the nozzle of the sprayer while applying in the field. Hence, special methods of transportation and packaging were required which made the field application inconvenient. Chen et al. [20] later prepared a new formulation of niclosamide named niclosamide salt wettable powder with a water suspension rate of $60 \%$. The molluscicidal effect of this formulation is twice as high as that of the $50 \%$ paste. Later on, the amino ethanol salt of niclosamide, called Bayluscide, slightly improved the water solubility of niclosamide. In 1986, the Institute of Parasitic Diseases, Sichuan Academy of Medical Sciences successfully developed a novel long-lasting molluscicide, i.e. a $10 \%$ controlled-release niclosamide formulation. In 1992, the 50\% niclosamide ethanolamine salt wettable powder was introduced and produced in China during WBLP due to its excellent suspension in water and strong molluscicidal effect. It is the most commonly used molluscicide in China at present. However, water is required for application of the formulation limiting its use in regions lacking water. Recently, a 4\% niclosamide ethanolamine salt powder was developed as a supplement of niclosamide ethanolamine salt [21]. It can overcome the difficulty of limited water resources, and will further expand the application range of niclosamide.

Many similar studies have been carried out to evaluate the molluscicidal effect of different molluscicides in field trials in China. Due to the variation of environmental settings, a large variety of the molluscicidal effects on snail mortality (40-100\%) no doubt impact the government decision makers to formulate the snail control strategy. Therefore, we conducted a systematic review and meta-analysis to assess the molluscicidal effect of the currently recommended $50 \%$ niclosamide ethanolamine salt wettable powder and of the new $4 \%$ niclosamide ethanolamine salt powder.

\section{Methods}

A systematic search of the Chinese literature, including documents published from January 1, 1990 to April 1, 2010, was conducted to capture data on molluscicidal effect on snail mortality by niclosamide in field trials in China.

\section{Search strategy and data source}

Three major Chinese literature databases, namely Chinese Biomedical Database, VIP Database and Wanfang Database, were jointly searched for data pertaining to molluscicidal effect of the $50 \%$ niclosamide ethanolamine salt wet powder or the $4 \%$ niclosamide ethanolamine salt powder in field trials in China. Since the databases are domestic, the language of publication was Chinese. We used the terms "niclosamide", or "Luomiecide (the 50\% niclosamide ethanolamine salt wettable powder)", or "Qiangluocide (the $4 \%$ Niclosamide ethanolamine salt powder)" and "molluscicide", or "snail control". The abstracts of each screened publication were read carefully.

\section{Criteria of inclusion and exclusion}

Both inclusion criteria and exclusion criteria for searching published literature were settled in the first stage of the meta-analysis. The inclusion criteria of published literature were as follows: (1) the $50 \%$ niclosamide ethanolamine salt wettable powder or the $4 \%$ niclosamide ethanolamine salt powder was used; (2) molluscicidal experiments carried out in marshland; (3) the used dose of niclosamide in the field was $2 \mathrm{~g} / \mathrm{m}^{2}$; (4) molluscicidal effects on mortality of $O$. hupensis were evaluated 3 days, 7 days or 15 days post drug application.

The exclusion criteria of published literature were as follows: (1) application dosage of $2 \mathrm{~g} / \mathrm{m}^{2}$ was not standardized or used in a wrong approach; (2) no original 
data, such as number of observations and number of dead snails, were published in the paper; (3) review article, or books or conference abstracts; (4) editorials or letters to the editors without original data.

\section{Analysis of publication bias}

The conclusion we draw may be distracted if we do not consider the bias that may exist from the literature review. Among all the biases, the publication bias is more difficult to control and adjust for. Identification of the bias is particularly important for the future adjustment. We applied "Metabias" function to test for funnel plot asymmetry based on a linear regression method, where the method "linreg" is the statistical test based on a weighted linear regression of the treatment effect on its standard error [22].

\section{Heterogeneity test}

Heterogeneity in meta-analysis refers to the variation in study outcomes between studies. The classical measure of heterogeneity is Cochran's Q. The $\mathrm{I}^{2}$ statistic describes the percentage of variation across study that is due to heterogeneity rather than chance [23,24], with its estimated formula: $\mathrm{I}^{2}=100 \% \times(\mathrm{Q}-\mathrm{df}) / \mathrm{Q}$. If there is very little variation between studies, $\mathrm{I}^{2}$ will be low and a fixed effects model might be appropriate. An alternative approach, 'random effects', allows the study outcomes to vary in a normal distribution between studies. Many investigators consider the random effects approach to be a more natural choice than the fixed effects.

All statistical analyses were done in $R$ Package [25]. All ratios were double arcsine transformed by FreemanTukey method. Forest plot, also called confidence interval plot, is drawn by the function of "Forest".

\section{Results}

\section{Literature searched}

A total of 90 documents, with potential original data on molluscicidal effect by niclosamide in field trials in China, were identified. The flow diagram in Figure 1 shows the review process, including the number of papers identified and number for exclusion of documents according to criteria. A total of 23 [21,26-42], 22 [21,26-32,34-43] and 18 [21,26-32,34,35,37,38,40-42] studies from 18,18 and 15 papers pertaining to molluscicidal effect of the $50 \%$ formulate 3, 7 and 15 days after applying in the field were included, respectively. For the $4 \%$ one, 7 [21,26-30], $10[21,26-30,44,45]$ and 10 [21,26-30,44,45] studies from 7,8 and 8 papers were enrolled, respectively.

\section{Publication bias}

According to the metabias analysis results, all publications regarding two molluscicides indicated no publication bias

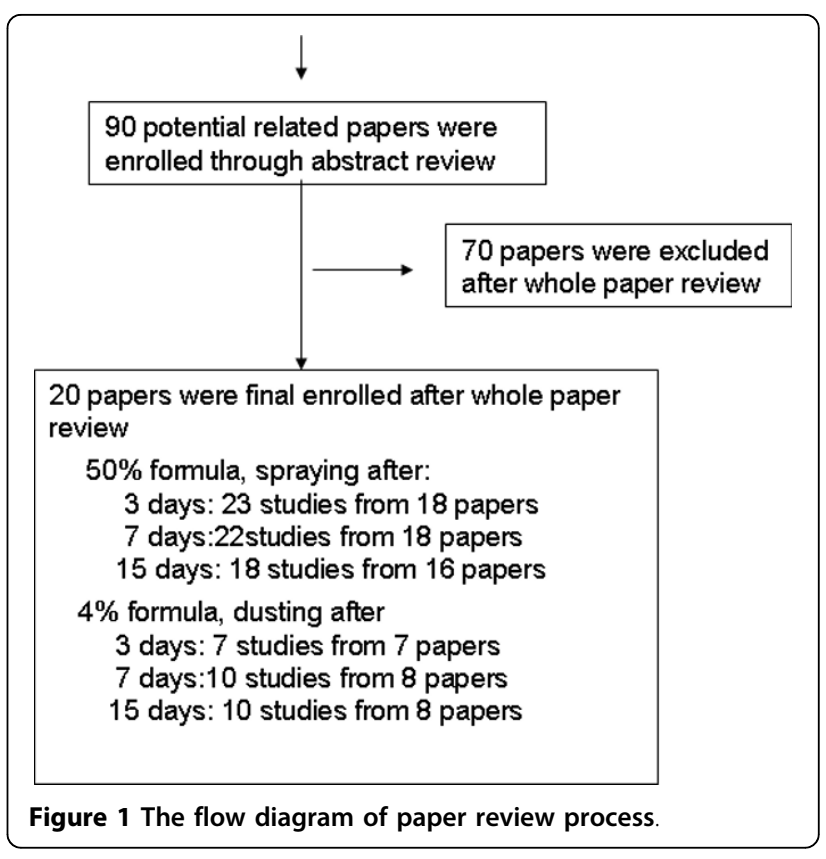

with all $p$ value higher than 0.05 . The linear regression figures showed all selected publications normally scattered around the regression line (Figure 2).

\section{Heterogeneity test}

The heterogeneity test indicated the existence of heterogeneity between studies. The $\mathrm{I}^{2}$ value of the $50 \%$ and $4 \%$ formulations studies 3, 7 and 15 days post application are all higher than 95\% (Table 1).

\section{Meta analysis}

The molluscicidal effect on snail mortality of the $50 \%$ and $4 \%$ formulations presented a wide range of values. For the $50 \%$ formulation, snail mortality 3,7 and 15 days after spraying ranged from $40-100 \%, 59-100 \%$ and $67-100 \%$, respectively. While for the $4 \%$ formulation, the snail mortality 3,7 and 15 days after dusting spanned from $46-97 \%, 51-98 \%$ and $78-99 \%$, respectively. The snail mortality of the $50 \%$ formulation after 3,7 and 15 days in the random effect model were 77\% [95\% CI: $0.68-0.86$ ], $83 \%$ [95\% CI: $0.77-0.89$ ], and $88 \%$ [95\% CI: $0.82-0.92]$, respectively. For the $4 \%$ formulation, the snail mortality 3, 7 and 15 days post application were 79\% [95\% CI: 0.61-0.93], 88\% [95\% CI: 0.79-0.95] and 93\% [95\% CI: 0.89-0.97], respectively (Figure 3-8).

\section{Discussion}

The present study, to our knowledge, represents the first systematic review and meta-analysis on molluscicidal effect of different formulations of molluscicides, i.e. the $50 \%$ niclosamide ethanolamine salt wettable powder, and the $4 \%$ niclosamide ethanolamine salt powder, 

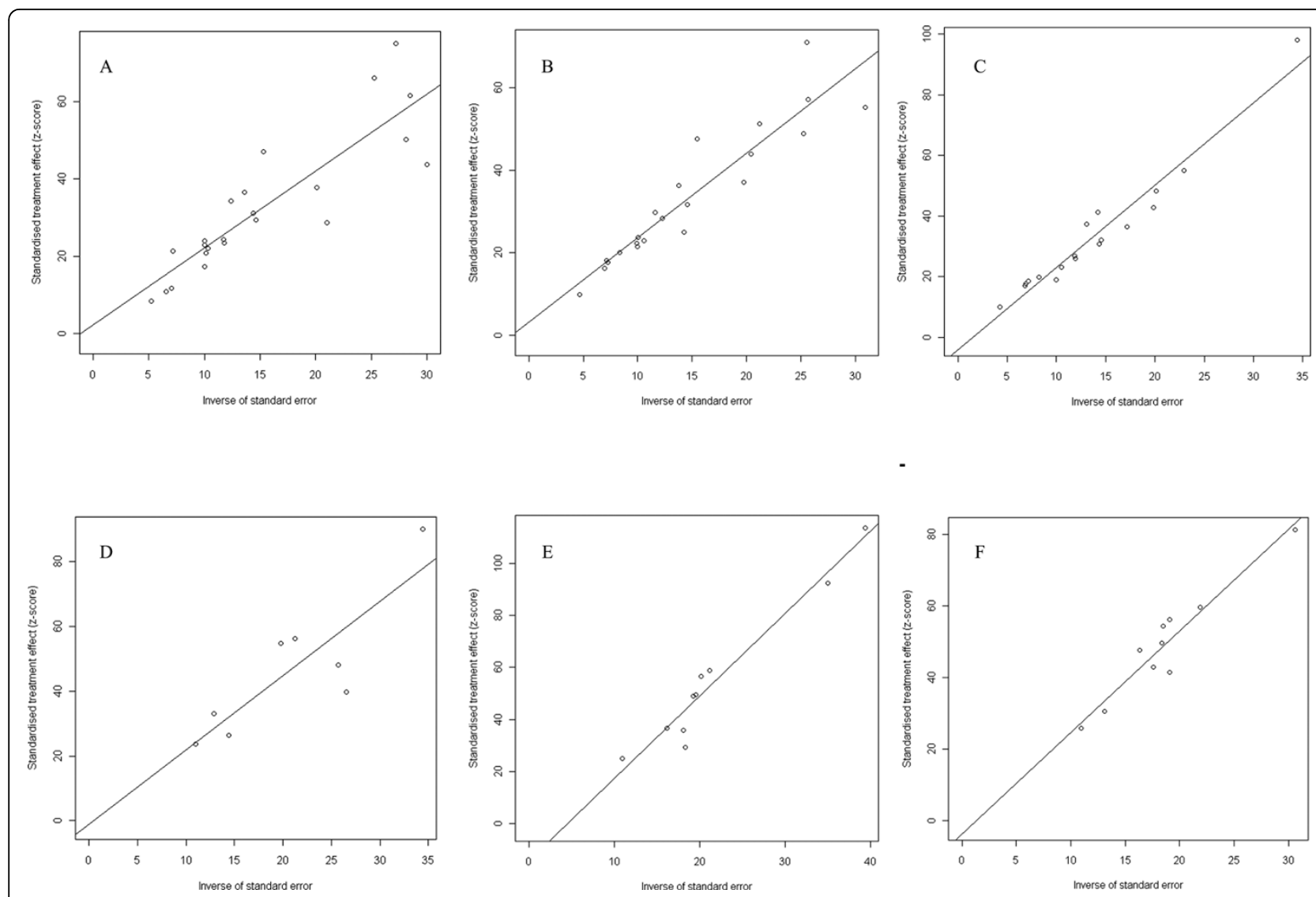

Figure 2 Linear regression test of funnel plot asymmetry for the $50 \%$ molluscicides niclosamide ethanolamine salt wettable powder 3 days (A), 7 days (B) and 15 days (C) post spraying, and for the $4 \%$ niclosamide ethanolamine salt powder 3 days (D), 7 days (E) and 15 days (F) post dusting, respectively. (A: $t=0.5716, \mathrm{df}=21, p$-value $=0.5737 ; \mathrm{B}: t=1.05, \mathrm{df}=20, p$-value $=0.30 ; \mathrm{C}: t=-1.66, \mathrm{df}=16, p$ value $=0.12 ; \mathrm{D}: t=-0.27, \mathrm{df}=5, p$-value $=0.80 ; \mathrm{E}: t=-2.25, \mathrm{df}=8, p$-value $=0.06 ; \mathrm{F}: t=-0.62, \mathrm{df}=8, p$-value $=0.56$ )

applied in the field of China. In the present meta-analysis, the publication biases were not detected in all study groups, which strengthens the likelihood that our metaanalysis was successful in including studies of a certain coverage and quality, which may have made results more comparable and reliable. The heterogeneity remained in each study group suggested that the application of the random effect model was optimal for our meta-analysis. Among the two formulations, the 50\% niclosamide ethanolamine salt wettable powder has been applied in the field for more than 20 years, and it was quite acceptable for the local use in mollusciciding owing to its excellent suspension in water and strong molluscicidal effect. So far, no evidence of drug resistance has been reported, which indicated the stability of the niclosamide product. But, several reports were on the disadvantages in the application of the $50 \%$ niclosamide ethanolamine salt wettable powder, particularly in

Table 1 Heterogeneous test results of the $50 \%$ niclosamide ethanolamine salt wettable powder and the $4 \%$ niclosamide ethanolamine salt powder (Freeman-Tukey double arcsine transformation used for proportions)

\begin{tabular}{|c|c|c|c|c|c|c|}
\hline Post-spraying (day) & $\operatorname{tau}^{2}$ & $\mathrm{H}$ & $\mathrm{I}^{2}$ & $\mathbf{Q}$ & df & $p$-value \\
\hline \multicolumn{7}{|l|}{$50 \%$ formulation } \\
\hline 3 & 0.27 & $8.66[7.97 ; 9.42]$ & $98.70 \%$ [98.40\%; 98.90\%] & 1651.76 & 22 & $<0.0001$ \\
\hline 7 & 0.14 & $6.12[5.50 ; 6.81]$ & 97.30\% [96.70\%; 97.80\%] & 785.58 & 21 & $<0.0001$ \\
\hline 15 & 0.10 & $4.91[4.29 ; 5.63]$ & $95.90 \%$ [94.60\%; 96.80\%] & 410.13 & 17 & $<0.0001$ \\
\hline \multicolumn{7}{|l|}{$4 \%$ formulation } \\
\hline 3 & 0.29 & $11.97[10.54 ; 13.6]$ & $99.30 \%$ [99.10\%; 99.50\%] & 859.97 & 6 & $<0.0001$ \\
\hline 7 & 0.14 & $8.59[7.54 ; 9.79]$ & $98.60 \%$ [98.20\%; 99.00\%] & 664.08 & 9 & $<0.0001$ \\
\hline 15 & 0.06 & $4.80[3.97 ; 5.80]$ & 95.70\% [93.70\%; 97.00\%] & 207.36 & 9 & $<0.0001$ \\
\hline
\end{tabular}




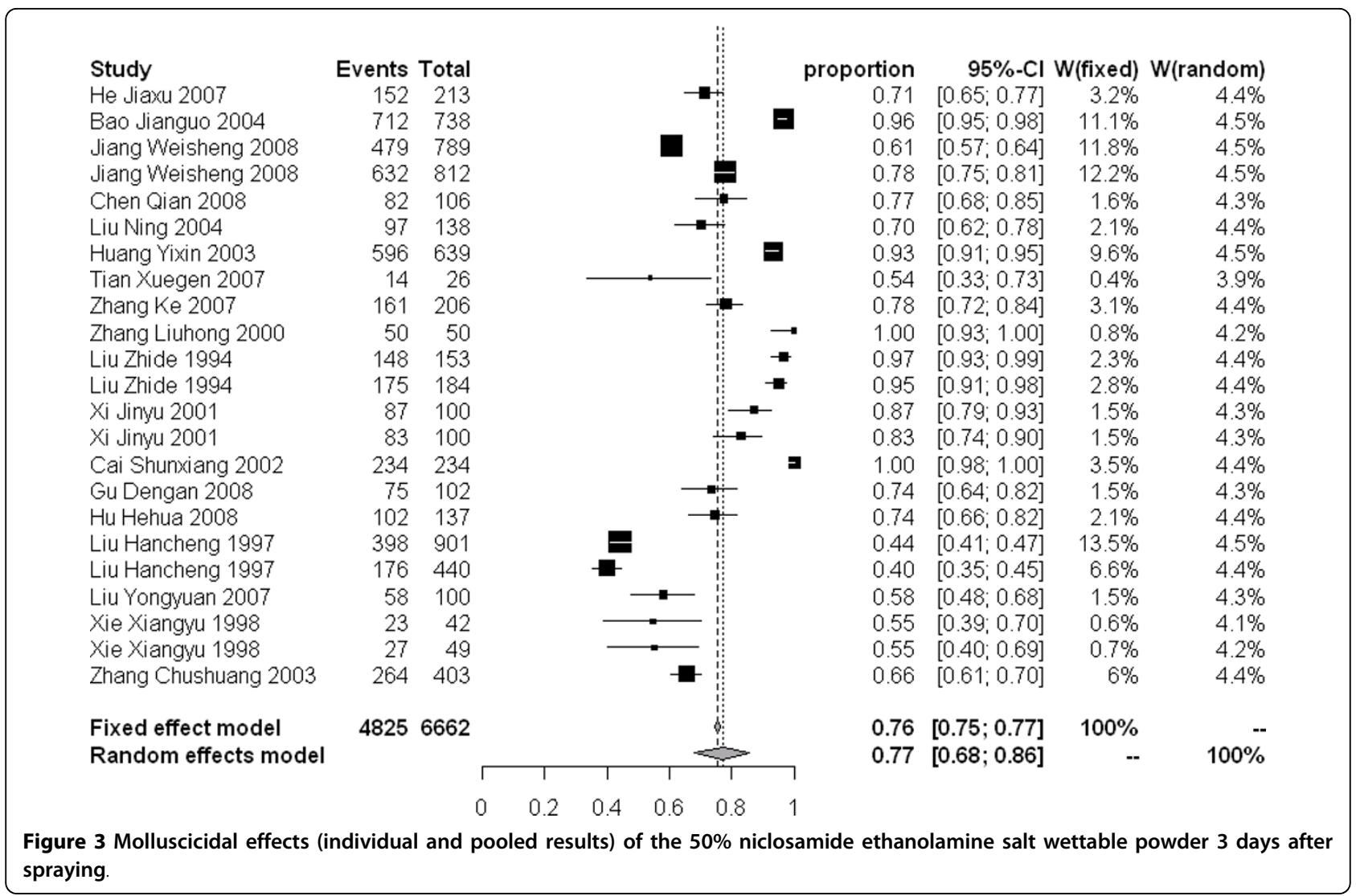

\section{Study}

He Jiaxu 2007

Bao Jianguo 2004

Jiang Weisheng 2008

Jiang Weisheng 2008

Chen Qian 2008

Liu Ning 2004

Huang Yixin 2003

Tian Xuegen 2007

$X i$ Jinyu 2000

Zhang Ke 2007

Zhang Liuhong 2000

Liu Zhide 1994

Liu Zhide 1994

Cai Shunxiang 2002

Gu Dengan 2008

Hu Hehua 2008

Liu Hancheng 1997

Liu Hancheng 1997

Liu Yongyuan 2007

Xie Xiangyu 1998

Xie Xiangyu 1998

Zhang Chushuang 2003

Fixed effect model

Random effects model

$\begin{array}{rr}\text { Events } & \text { Total } \\ 125 & 149 \\ 631 & 651 \\ 432 & 635 \\ 529 & 656 \\ 87 & 111 \\ 120 & 203 \\ 392 & 447 \\ 16 & 21 \\ 86 & 100 \\ 166 & 211 \\ 46 & 50 \\ 123 & 133 \\ 177 & 188 \\ 238 & 238 \\ 79 & 97 \\ 60 & 69 \\ 581 & 953 \\ 253 & 389 \\ 77 & 99 \\ 46 & 52 \\ 40 & 47 \\ 322 & 416\end{array}$

46265915

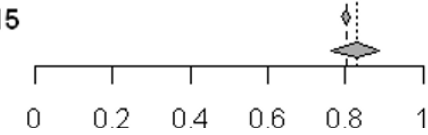

proportion $\quad 95 \%-\mathrm{Cl}$ W(fixed) W(random)

$0.84 \quad[0.77 ; 0.89] \quad 2.5 \% \quad 4.6 \%$

$0.97 \quad[0.95 ; 0.98] \quad 11 \% \quad 4.8 \%$

$0.68 \quad[0.64 ; 0.72] \quad 10.7 \% \quad 4.8 \%$

$0.81 \quad[0.77 ; 0.84] \quad 11.1 \% \quad 4.8 \%$

$0.78 \quad[0.70 ; 0.86] \quad 1.9 \% \quad 4.5 \%$

$0.59 \quad[0.52 ; 0.66] \quad 3.4 \% \quad 4.7 \%$

$0.88 \quad[0.84 ; 0.91] \quad 7.5 \% \quad 4.8 \%$

$0.76 \quad[0.53 ; 0.92] \quad 0.4 \% \quad 3.6 \%$

$0.86[0.78 ; 0.92] \quad 1.7 \% \quad 4.5 \%$

$0.79[0.73 ; 0.84] \quad 3.6 \% \quad 4.7 \%$

$0.92[0.81 ; 0.98] \quad 0.9 \% \quad 4.2 \%$

$0.92[0.87 ; 0.96] \quad 2.3 \% \quad 4.6 \%$

$0.94[0.90 ; 0.97] \quad 3.2 \% \quad 4.7 \%$

$1.00[0.98 ; 1.00] \quad 4 \% \quad 4.7 \%$

$0.81 \quad[0.72 ; 0.89] \quad 1.7 \% \quad 4.5 \%$

$0.87[0.77 ; 0.94] \quad 1.2 \% \quad 4.4 \%$

$0.61[0.58 ; 0.64] \quad 16.1 \% \quad 4.8 \%$

$0.65[0.60 ; 0.70] \quad 6.6 \% \quad 4.7 \%$

$0.78 \quad[0.68 ; 0.86] \quad 1.7 \% \quad 4.5 \%$

$0.88 \quad[0.77 ; 0.96] \quad 0.9 \% \quad 4.3 \%$

$0.85 \quad[0.72 ; 0.94] \quad 0.8 \% \quad 4.2 \%$

$0.77 \quad[0.73 ; 0.81] \quad 7 \% \quad 4.7 \%$

$\begin{array}{lrrr}0.80 & {[0.79 ; 0.81]} & 100 \% & - \\ 0.83 & {[0.77 ; 0.89]} & -- & 100 \%\end{array}$

Figure 4 Molluscicidal effects (individual and pooled results) of the $50 \%$ niclosamide ethanolamine salt wettable powder 7 days after spraying. 


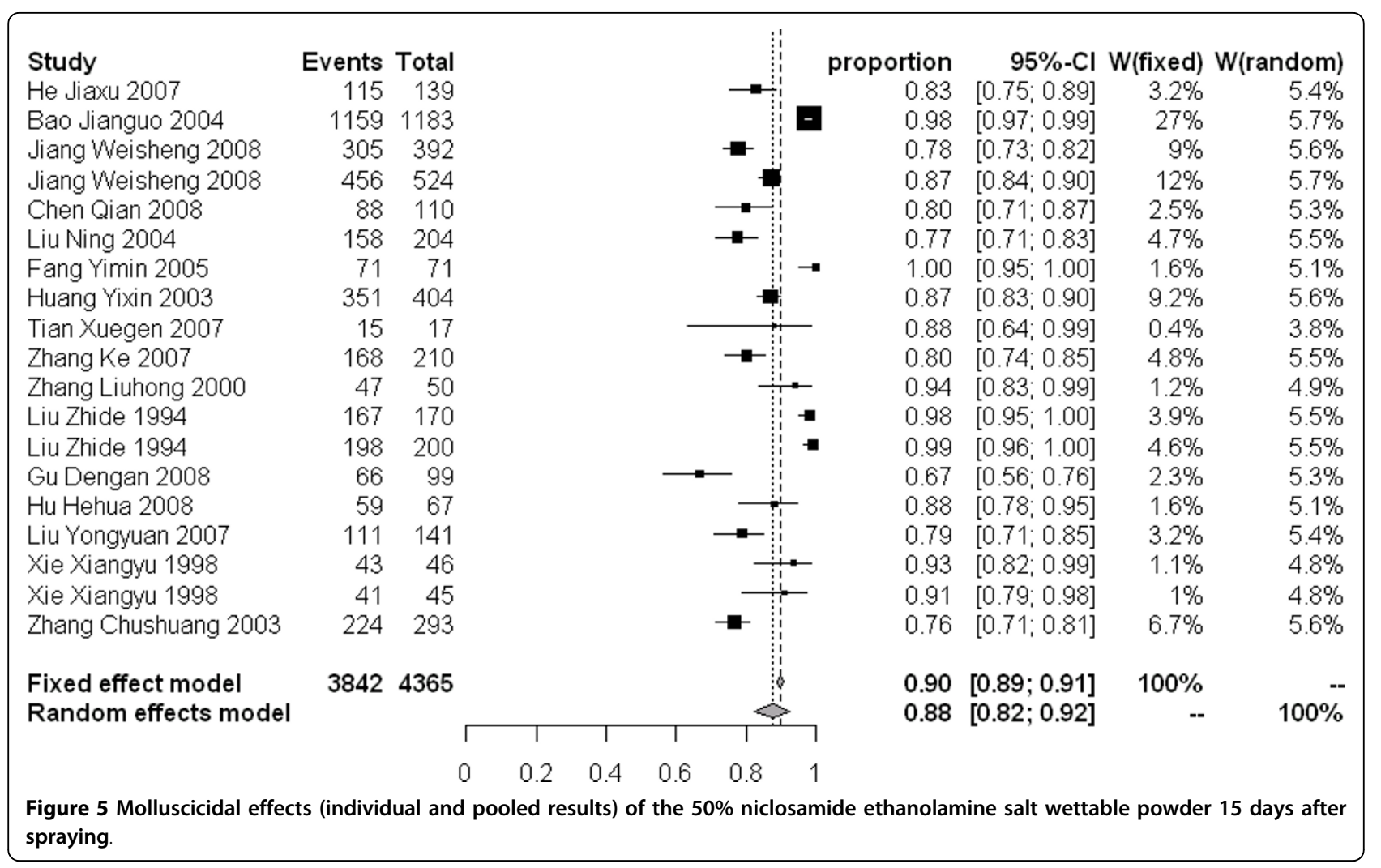

regions without water supply $[29,44]$. The $4 \%$ niclosamide ethanolamine salt powder is a newly formulated product, and is able to overcome the problems of water shortage as well as of blocking equipment during application.

Our systematic review and meta-analysis identified that the molluscicidal effect of both formulations are suitable for the mollusciciding in schistosomiasis control programme, causing snail mortality over $88 \% 15$ days after application. The molluscicidal effects of the $4 \%$ formulation are slightly higher than those of the $50 \%$ formulation 3, 7 and 15 days after spraying, respectively. However, the numbers of studies utilized in our metaanalysis for the $50 \%$ formulation was almost twice the number of the $4 \%$ formulation, which indicated the results of the $50 \%$ formulation are more stable and reliable. Therefore, in the future, it is recommended that more field observations on molluscicidal effect of the $4 \%$ formulation need to be carried out in various environmental settings.

Currently, schistosomiasis japonica is mainly prevalent in lake and marshland regions and part of the hilly and

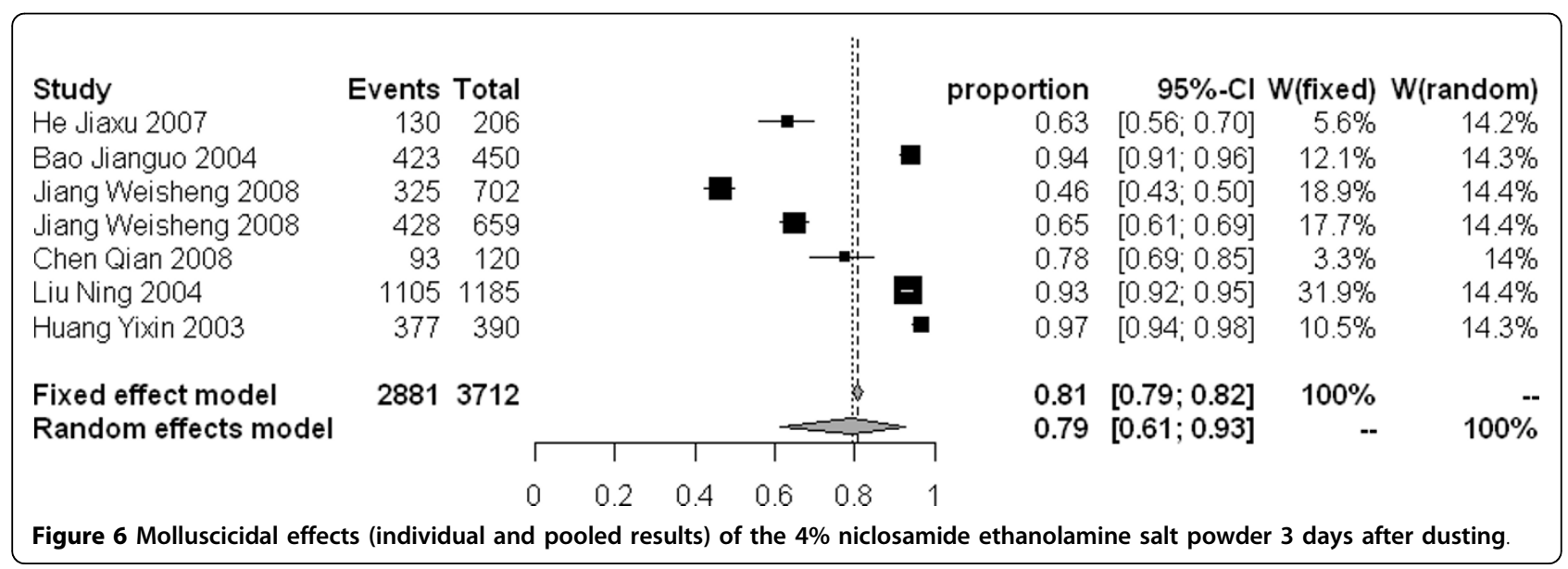




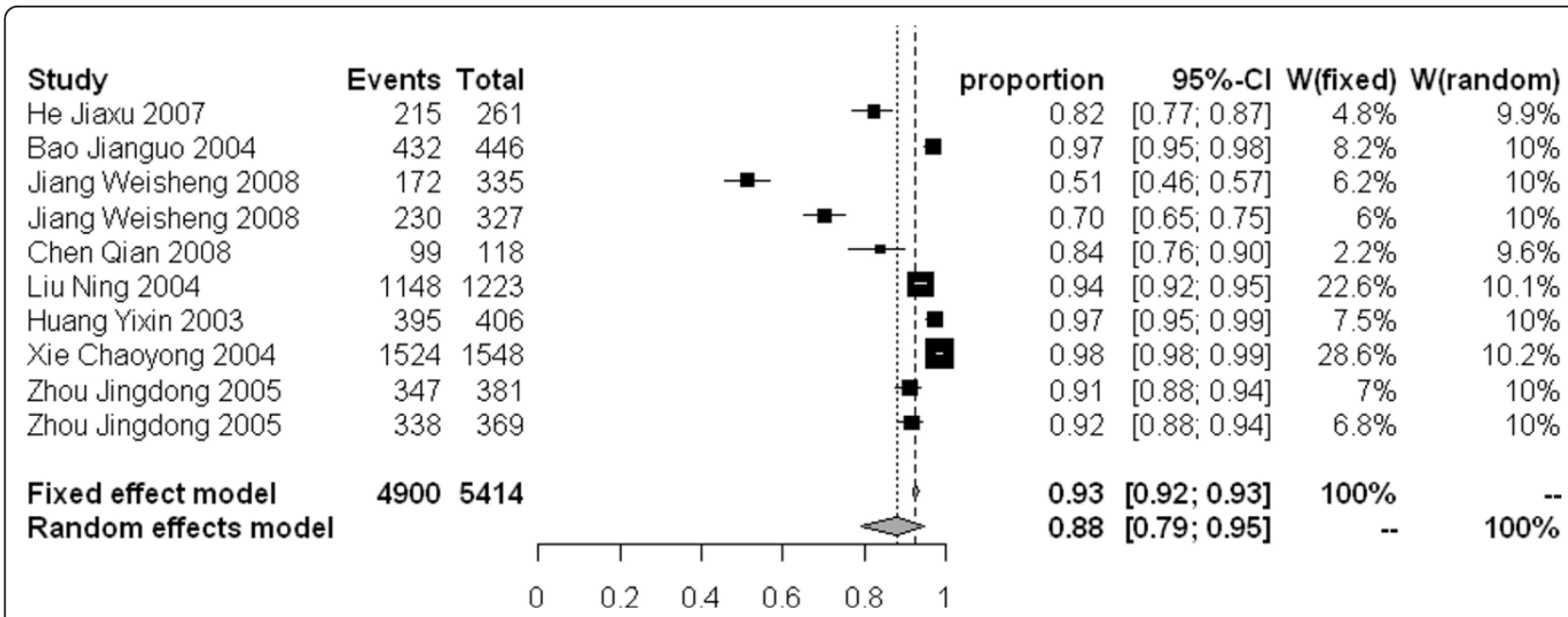

Figure 7 Molluscicidal effects (individual and pooled results) of the $4 \%$ niclosamide ethanolamine salt powder 7 days after dusting

mountainous regions of China[2]. In the lake and marshlands regions, snails spread out in vast areas of the Yangtze River basin, which are flooded for about 2 to 5 months per year. In the hilly and mountainous regions, the snails are distributed along ditches, irrigation channels and river systems, but are isolated from one another $[2,46]$. In spite of the $50 \%$ formulation as the most frequent used molluscicide over decades in China [20,47], its molluscicidal effect could be impeded due to the shortage of water. While the $4 \%$ formulation can become a surrogate of the $50 \%$ formulation, with its advantage of application in the areas shortage of water [47]. Therefore, it is convenient for the $50 \%$ formulation applied in the lake and marshland region as well as the plain region with water networks owing to the rich water supply, while the application of the $4 \%$ formulation in the hilly and mountainous region, where there is difficulty in water access, is more practical and efficient. Unfortunately, in this study, we do not have enough references of the mollusciciding applied in hilly and mountainous region to test the above hypothesis.

Although this systematic review and meta-analysis identified that the molluscicidal effect of both formulations of niclosamide are good enough for the mollusciciding in a schistosomiasis control programme, both formulations cannot produce $100 \%$ snail mortality. Meta-analysis results showed that the snail mortality of the $50 \%$ and $4 \%$ formulations are $88 \%$ and $93 \%$, respectively, 15 days after applying. It indicates the low density of $O$. hupensis snails would survive following the one spray in the snail control activity. According to the law of biological growth and development, density dependency (negative feedback) plays an important role for the population dynamics. There is a general consensus among ecologists that small

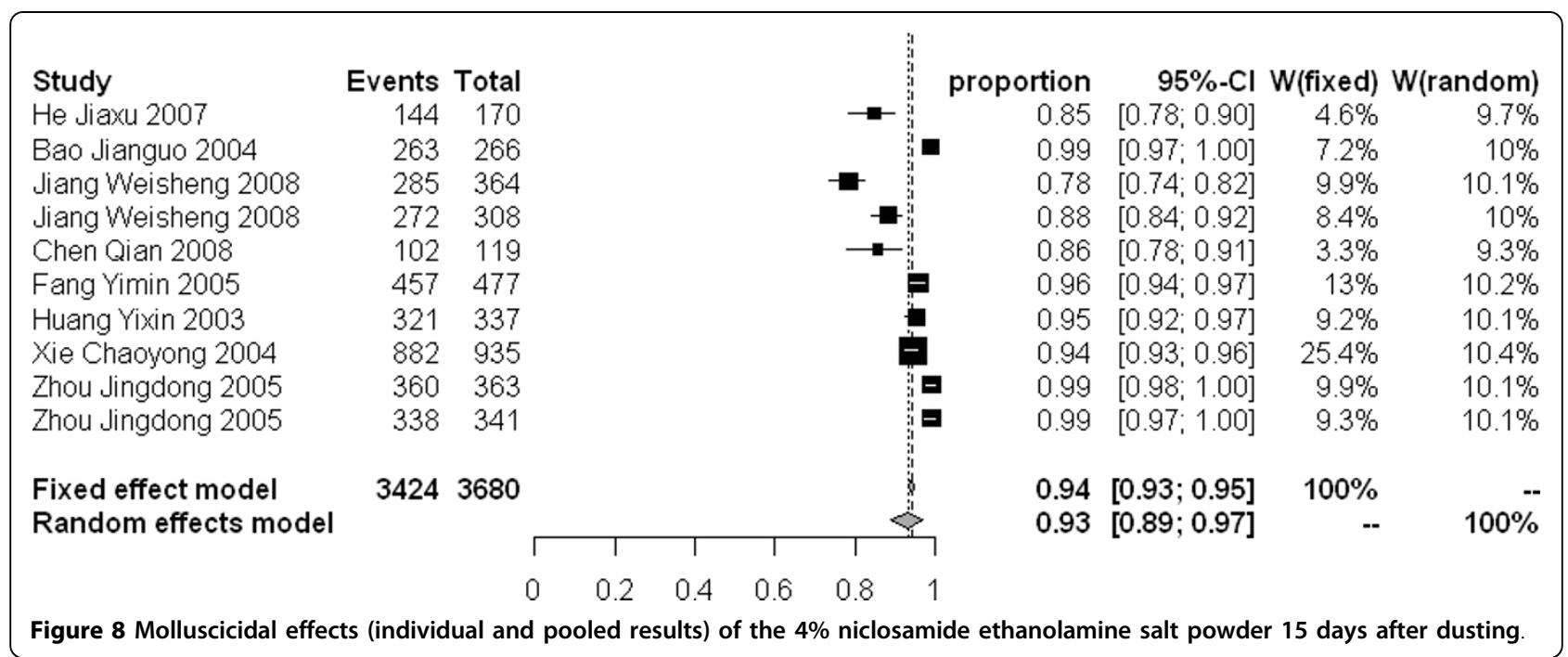


arthropods or invertebrate animals will follow the Gompertz logistic (GL) reproduction model, which means high turn-over rates occurred at low density [48,49]. Therefore, an assumption can be drawn that if mollusciciding is only attempted once by spraying niclosamide in the field, the survival of few snails will re-bounce following GL negative feedback in the coming years, which make mollusciciding as one of control strategies display low cost-effectiveness. In order to consolidate snail control achievement in terms of keeping snail density at a certain lower level or even elimination of $O$. hupensis snails in the field, it is recommended to perform mollusciciding more than twice annually. While studies on the optimal times of annual mollusciciding to eliminate $O$. hupensis over certain years is still unknown and we need further investigations on the ecology of $O$. hupensis to understand its dynamics.

\begin{abstract}
Acknowledgements
This project received the grants from the UNICEF/UNDP/World Bank/WHO Special Programme for Research and Training in Tropical Diseases (TDR) (grant No. A70530), National S\&T Supporting Project (2007BAC03A02), and the National Important Sci-tech Special Projects (No. 2008ZX10004-011). We sincerely thank two anonymous referees and Professor Chris Arme for their series of excellent comments.
\end{abstract}

\section{Author details}

${ }^{1}$ Jiangsu Institute of Parasitic Diseases, Meiyuan Yangxiang 117, Wuxi 214064, Jiangsu, People's Republic of China. 'National Institute of Parasitic Diseases, Chinese Center for Disease Control and Prevention, 207 Rui Jin Er Road, Shanghai 200025, People's Republic of China.

\section{Authors' contributions}

GJY and XNZ conceived and wrote the first version of the manuscript. GJY, WL, LPS, FW, KY and YXH revised the manuscript. XNZ and GJY finalized the manuscript. All of authors read and approved the final version of the manuscript.

\section{Competing interests}

The authors declare that they have no competing interests.

Received: 25 June 2010 Accepted: 7 September 2010

Published: 7 September 2010

\section{References}

1. Mao CP, Shao BR: Schistosomiasis control in the People's Republic of China. Am J Trop Med Hyg 1982, 31:92-99.

2. Mao CP: Biology of Schistosome and Control of Schistosomiasis. Beijing: People's Health Press 1990, (in Chinese)

3. Zhou XN, Wang LY, Chen MG, Wu XH, Jiang QW, Chen XY, Zheng J, Utzinger J: The public health significance and control of schistosomiasis in China - then and now. Acta Trop 2005, 96:97-105.

4. Utzinger J, Zhou XN, Chen MG, Bergquist R: Conquering schistosomiasis in China: the long march. Acta Trop 2005, 96:69-96.

5. Maegraith B: Schistosomiasis in China. Lancet 1958, 271:208-214.

6. Yuan HC, Guo JG, Bergquist NR, Tanner M, Chen XY, Wang HZ: The 19921999 world bank schistosomiasis research initiative in China: outcome and perspectives. Parasitol Int 2000, 49:195-207.

7. Liang S, Yang CH, Zhong B, Qiu DC: Re-emerging schistosomiasis in hilly and mountainous areas of Sichuan, China. Bull World Health Organ 2006, 84:139-144.

8. Wang LD, Chen HG, Guo JG, Zeng XJ, Hong XL, Xiong JJ, Wu XH, Wang XH, Wang LY, Xia G, Hao Y, Chin DP, Zhou XN: A strategy to control transmission of Schistosoma japonicum in China. N Engl J Med 2009 360:121-128.
9. Wang LD, Guo JG, Wu XH, Chen HG, Wang TP, SP Z, Zhang ZH, Steinmann $P$, Yang GJ, Wang SP, Wu ZD, Wang LY, Hao Y, Bergquist $R$, Utzinger J, Zhou XN: China's new strategy to block transmission of schistosomiasis and beyond. TMIH 2009, 14:1475-1583.

10. Sturrock RF, Kinyanjui H, Thiongo FW, Tosha S, Ouma JH, King CH, Koech D, Siongok TK, Mahmoud AA: Chemotherapy-based control of schistosomiasis haematobia. 3. Snail studies monitoring the effect of chemotherapy on transmission in the Msambweni area, Kenya. Trans $R$ Soc Trop Med Hyg 1990, 84:257-261.

11. Sturrock RF, Klumpp RK, Ouma JH, Butterworth AE, Fulford AJ, Kariuki HC, Thiongo FW, Koech D: Observations on the effects of different chemotherapy strategies on the transmission of Schistosoma mansoni in Machakos District, Kenya, measured by long-term snail sampling and cercariometry. Parasitology 1994, 109(Pt 4):443-453.

12. Malone JB: Biology-based mapping of vector-borne parasites by geographic information systems and Remote Sensing. Parassitologia 2005, 47:27-50.

13. Zhou XN, Yang GJ, Yang $K$, Wang $X H$, Hong QB, Sun LP, Malone JB, Kristensen TK, Bergquist NR, Utzinger J: Potential Impact of Climate Change on Schistosomiasis Transmission in China. Am J Trop Med Hyg 2008, 78:188-194.

14. Gao LL: Considerations on snail control by environmental modification in Zhejiang province. Chin J Schisto Cont 2002, 14:299-302, (in Chinese).

15. Zhou XN, Yang GJ, Sun LP, Hong QB, Yang K, Wang RB, Hua ZH: Potential impact of global warming on the transmission of schistosomiasis. Chin J Epidemiol 2002, 23:83-86, (in Chinese).

16. Xu XJ, Wei FH, Yang XX, Dai YH, Yu GY, Chen LY, Su ZM: Possible effects of the Three Gorges dam on the transmission of Schistosoma japonicum on the Jiang Han plain, China. Ann Trop Med Parasitol 2000, 94:333-341.

17. Chen XY, Wang LY, Cai JM, Zhou XN, Zheng J, Guo JG, Wu XH, Engels D, Chen MG: Schistosomiasis control in China: the impact of a 10-year World Bank Loan Project (1992-2001). Bull World Health Organ 2005 83:43-48.

18. WHO: The role of mollusciciding in schistosomiasis control. Geneva: WHO 1983, 72-73.

19. Perrett $\mathrm{S}$, Whitfield PJ: Currently available molluscicides. Parasitol Today 1996, 12:156-159.

20. Chen C: Molluscicides and their application in China. Chin J Schisto Cont 2003, 321-322, (in Chinese).

21. He JX, Wang H, Wu MY, Chen XF, Shu QM, Tao W, Xu YX, Zhang SQ: Observation on the molluscicidal effect of niclosamide ethanolamine salt dustable powder by dusting in fields. J Trop Dis Parasito 2007, 5:153-154, (in Chinese)

22. Egger M, Davey Smith G, Schneider M, Minder C: Bias in meta-analysis detected by a simple, graphical test. BMJ 1997, 315:629-634.

23. Higgins JP, Thompson SG: Quantifying heterogeneity in a meta-analysis. Stat Med 2002, 21:1539-1558.

24. Higgins JP, Thompson SG, Deeks JJ, Altman DG: Measuring inconsistency in meta-analyses. BMJ 2003, 327:557-560.

25. R: A language and environment for statistical computing. [http://www.Rproject.org], searched on July 31, 2010.

26. Bao JG, Zhang GH, Wu WD, Zhang SQ, Zhang XY, LV DB, Fang GR, Wang FF, Zhu L, Dai QJ: Snail control effect of $4 \%$ powder of niclosamide ethanolamine salt in field trial. Parasito Infec Dis 2004, 2:163-165, (in Chinese).

27. Chen Q, Tian B, Zhang ZQ, Li DX, Gao Y: Effect of killing snails in marshland areas using Qiangluocide power in spring. J Path Bio 2008 162-163, (in Chinese).

28. Huang YX, Sun LP, Hong QB, Gao Y, Zhang K, Yang K, Wu F: Evaluation on molluscicideal effect of qiangluocide powder by dusting in fields. Chin J Schisto Cont 2003, 15:434-438, (in Chinese).

29. Jiang WS, Zeng XJ, Yi FY, Li SJ: Molluscicidal effect of $4 \%$ niclosamide ethanolamine salt dustable powder in Poyang Lake region. J Trop Dis Parasito 2008, 6:230-231, (in Chinese).

30. Liu N, Xu GK, Zhang K, Wang B, Wang WP: Molluscicidal effect of qiangluocide powder by dusting in marshland. Chin J Schisto Cont 2004 16:144-145, (in Chinese).

31. Liu ZD, Liu YM, Lin DD, Huang QS: Laboratory and field observations on molluscicidal effect of niclosamide and santobrite. Chin J Schisto Cont 1994, 6:82-84, (in Chinese). 
32. Tian XG, Pan XP, Ke ZM, An JS, Chen DY, Ruan B, He LZ, Gao SB: Study on molluscicide effect of niclosamide with different methods in the field. $J$ Trop Dis Parasito 2007, 5:97-98, (in Chinese).

33. Xi JY, Meng XH, Wu ZS, Liu XR, Li DM, Tang CX: Comparison of molluscicidal effects of niclosamide products from Sichuan and Anhui. J Prac Parasit Dis 2001, 9:162-163, (in Chinese).

34. Zhang K, Hou N, Zhang QP, Wang B, Liu SH: Study on molluscicidal effect of niclosamide ethanolamine salt dustable powder against Oncomelania snail in marshland. Chin J Schisto Cont 2007, 19:1, (in Chinese).

35. Zhang LH, Pan HF, Wang YK: Field application of niclosamide ethanolamine salt wettable powder. Zhejiang Prev Med 2000, 12:33, (in Chinese).

36. Cai SX, XU XJ, Liu HC, Wei FH, Liu JB, Fu Y, Cao MM: Laboratory and field trials on molluscicidal effect of niclosamide, shachongcide and metaldehyde. Chin J Schisto Cont 2002, 266-269, (in Chinese).

37. Gu DA, Zhang ZH, Yan ZW, Zhou XN, Xu XW, Ai SY, Zhang H: Comparison of molluscicidal effect and cost-effect of Rongbao and niclosamide. Chin J Schisto Cont 2008, 106-109, (in Chinese).

38. Hu HH, Li DJ, Xia HB, Liu X, Liu J: Molluscicidal effect of Robao applied in the marshland regions. J Trop Dis Parasito 2008, 159-160, (in Chinese).

39. Liu HC, Fu Y, Huang XB, Xiao WS, Peng DY, Li SS, Qin ZH, Yu BX, Xiao GL, Zhu SH: Molluscicidal effects of niclosamide by dusting and spraying. J Prac Parasit Dis 1997, 41-42, (in Chinese).

40. Liu YY, Xu HG, Hua XT, Li NH: Molluscicidal effect of suspension concentrate of niclosamide in the field. J Trop Dis Parasito 2007, 111-112 (in Chinese).

41. Xie XY: Observation and application of molluscicidal effect of niclosamide ethanolamine salt wettable powder. J Prac Parasit Dis 1998, 92, (in Chinese).

42. Zhang CS, Li GP, Yang GF, Wei WY: Experiments of molluscicidal effect of suspension concentrate of niclosamide against Oncomelania snails. Chin J Schisto Cont 2003, 291-293, (in Chinese).

43. Xi JY, Cai DQ, Zuo SH, Lu YS, Li SQ, Zhou JM, Luo YJ: Cost-effective comparison between niclosamide slow releasing formula and wettable powder. Chin J Schisto Cont 2000, 12:364-366, (in Chinese).

44. Xie CY, Gao Y, Zong ZM, Qiu L, Yin WG, Sun LP, Huang YX: Molluscicidal effect of niclosamide ethanolamine salt dustable powder by dusting in Autumn. Chin J Schisto Cont 2004, 298-299, (in Chinese).

45. Zhou JD: Emergency mollusciciding by application of niclosamide ethanolamine salt dustable powder in flooding. Sh J Prev Med 2005, 581, (in Chinese).

46. Zhou XN: Science on Oncomelania snail. Beijing: Science press 2005, (in Chinese).

47. Xu SF, Wang H, Jiang LX: Progress of research on various preparations of niclosamide and snail control. Chin J Schisto Cont 2005, 17:478-480, (in (hinese).

48. Brook BW, Bradshaw CJ: Strength of evidence for density dependence in abundance time series of 1198 species. Ecology 2006, 87:1445-1451.

49. Yang GJ, Bradshaw CJA, Whelan PI, Brook BW: Importance of endogenous feedback controlling the long-term abundance of tropical mosquito species. Popul ecol 2008, 50:293-305.

doi:10.1186/1756-3305-3-84

Cite this article as: Yang et al:: Molluscicidal efficacies of different formulations of niclosamide: result of meta-analysis of Chinese literature. Parasites \& Vectors 2010 3:84.

\section{Submit your next manuscript to BioMed Central and take full advantage of:}

- Convenient online submission

- Thorough peer review

- No space constraints or color figure charges

- Immediate publication on acceptance

- Inclusion in PubMed, CAS, Scopus and Google Scholar

- Research which is freely available for redistribution

Submit your manuscript at www.biomedcentral.com/submit 